\title{
The Robustness of Agile C2 Organizations
}

\author{
Yao Yang, Bao-Xin Xiu, Ting-Ting Yang, Wei-Ming Zhang and Wei-Dong Bao \\ Science and technology on Information Systems Engineering Laboratory, National University of Defense \\ Technology, ChangSha, HuNan, China \\ 392387247@qq.com
}

\begin{abstract}
Agility is arguably one of the most important characteristics of successful Information Age organizations. The study of agility organizations is currently one of the hottest topics in the organization study field. In this paper, we first put forward an agile command and control (C2) organization model and then focus on the robustness of the agile $\mathrm{C} 2$ organization. We set a method to measure the $\mathrm{C} 2$ organization agility. Then experiment has been taken to verify the method and analysis the agility of a given organization
\end{abstract}

Index Terms - Agility, agile $\mathrm{C} 2$ organization, force organizations, robustness.

\section{INTRODUCTION}

Agility is arguably one of the most important characteristics of successful Information Age organizations [1]. With a wider use of information and network technology in the modern social life, new organizational concepts and patterns are coming out, such as network organization, virtual enterprise, agile manufacturing system, spirituality organization and hyperlinks organization tissue [1,4] and so on. These new type organization concepts and patterns broke through the traditional geographical restrictions, organizational resource limitations and restrictions on traditional structure. They present the characteristics of distribution, flattening, flexibility and autonomy of organizations.

Meantime, in the C2 filed, the uncertainty and asymmetry of the battlefield environment lead to the increase of the complexity of the military activity. New types of organization patterns such as the network centric warfare, the "Power to the Edge" [1] and other new type organization pattern appear.

"Power to the Edge" pattern means to organize all the resources and opportunities to present the best power. To cope with the complexity and the uncertainty of the external environment it constantly changes and evolves the organizational structure and behavior. We name the C2 organization, which can implement the "Power to the Edge" pattern, agile C2 organization.

Scholars have done a lot of work on research of the organization. In the early 1990s, Kathleen proposed a theory named Computational and Mathematical Organization found (CMOT) [5]. The basic idea of this theory is the essence properties of human organization can also be calculated. This theory adopts the method of computational mathematics to study human organization (also called natural organization) in the form of computing entities.

The Computational Analysis of Social and Organizational Systems (CASOS) center and Institute for Complex Engineered Systems (so-called ICES) of Carnegie - Mellon University used CMOT theory in the military field. They attempt to describe and analyze the forces organization and provide a basis for the construction of forces organization. They proposed the organization model of PCANS [6], the forces organization topology model based on PCANS [7] and the model of adaptive organizational behavior based on Simulated Annealing algorithm [8, 9]. These models are mainly for the description and analysis of the organization and its behavior. They are not able to guide the organization of the design effectively.

"Power to the Edge" is firstly proposed by Alberts and Hayesin in 2003. This new kind of organization mode has the characteristics of two aspects. One is to achieve interoperability; the second is to achieve agility. Later in 2011, they propose a set of experiment $\mathrm{s}$ based on their ELICIT to find out the way to measure the agility. But still no clear agile C2 organization model has been proposed. Using system engineering technology to design a task orientation organization is the main method to implement the series A2C2 experiments designed by the American army. University of Connecticut and Aptima Company have made great work on its theory, method and technology. But still not reflects the nature of the agile C2 organization.

U.S. navy information age war expert Jeffrey r. Cares has analyzed the research of the characteristic and the insufficiency of current network centric warfare model and puts forward a information age combat model [11] based on the complex network theory. Anthony h. Dekker et al. from Australia's Defense, Science and Technology Organization (DSTO) introduce social network analysis method to the $\mathrm{C} 2$ organization research field based on the idea CMOT theory. They establish a new model to descript networked organizational combat named FINC (Force, Intelligence, Networking and C2) [12]. The current researches of network theory mainly focus on the organization description and the analysis of the characteristics of the network. Less work has been done on how to construct the organization.

To sum up, the research on agile C2 organization is mostly embodied in the aspect of theoretical research and no clear model or method has been proposed to realize the agile C2 organization. In this paper, we first put forward an agile command and control (C2) organization model and then focus on the robustness of the agile $\mathrm{C} 2$ organization.

This paper is structured as follows: Section 1 is an 
introduction, in this part we briefly introduced the related research, Section 2 is the agile C2 organization model, Section 3 is the study of the robustness of the agile C2 organization, Section 4 is the experiments and analysis, and Section 5 is conclusion.

\section{AGILE C2 ORGANIZATION MODEL}

The agile C2 organization model contains four parts: mission-task model, structure-function model, and state-transform model.

The mission-task model describes all the missions and tasks of an agile C2 organization.

Definition 1 Mission-task space M represent for all possible tasks of an organization, defined as:

$$
M=\left\{\left\{T_{i}\right\}\right\}
$$

Where $T_{i}$ is a task.

The structure-function model describe the structure and basic function of a organization

Definition 2 Structure model $O_{\text {struct }}$ contains the entities and their relationships, defined as:

$$
O_{\text {struct }}=<D, E, C, R_{d, e}, R_{d, d}, R_{d, c, d}>
$$

Where $\mathrm{D}$ is the decision entity set, $\mathrm{E}$ is the execution entity set, $\mathrm{C}$ is the communication entity set, $R_{d, e}$ is the control relationship set, $R_{d, d}$ is command relationship, $R_{d, c, d}$ is the cooperation relationship.

Definition 3State model describes the present state of the organization, including the current tasks, structure and function, and the force organizations.

$$
O_{\text {state }}=<\left(T_{s}, O_{s}\right), O_{s-\text { struct }}, O_{s-\text { funct }}>
$$

Where $T_{s}=\left\{T_{i}\right\}$ is the current tasks and $O_{s}=\left\{O_{i}\right\}$ is the force organization. $O_{i}$ is the sub organization of an agile organization.

Definition 4 Transform model describes of an organization transform from one state to another, defined as:

$$
O_{\text {trans }}\left(O_{\text {state }}\right) \rightarrow O_{\text {state }}
$$

Definition 5The agile organization model AO defined as:

$$
A O=<M, O_{\text {struct }}, O_{\text {funct }}, O_{\text {state }}, O_{\text {trans }}>
$$

\section{THE STUDY OF ROBUSTNESS OF AN AgILE C2 ORGANIZATION}

Robustness is derived from control theory. It means the running environment can have certain deviations on the default environment. As long as these deviations are within the allowable deviation, a robust control system can run as be expected. The robustness of the organization should have the same meaning.

Definition 6 The robustness of the force organization describe the task complete ability of the force orgnization with unchangeable structure when the task changed, defined as:

$$
A_{f-\text { robus }}=R_{-} C_{f}
$$

$R_{-} C_{f}$ is defined as follows. Suppose an existing force organization $\mathrm{O}_{f}$ has the resources $\left\{\left(r_{1}, N_{r_{1}}\right), \ldots,\left(r_{n}, N_{r n}\right)\right\}$. Where $r_{1}$ is the ID of a certain resource and $N_{r_{1}}$ is the amount of the resourse. And resources required by the tasks in the task-mission space of the organization is $\left\{\left(r_{1}, \operatorname{NMax}_{r_{1}}\right), \ldots,\left(r_{n}, \operatorname{NMax}_{r n}\right)\right\}$.

Then $R_{-} C_{f}$ is defined as:

$$
R_{-} C_{f}=\frac{\sum_{i} N_{r_{i}} / N M a x_{r_{i}}}{n}
$$

So $R_{-} C_{f}$ measures to what degree the force organization can complete all possible tasks without changing the structure. That is the robustness of the force organization.

Definition 6 The robustness of the organization describe the task complete ability of the organization with unchangeable structure when the task changed, defined as:

$$
\left\{\begin{array}{l}
A_{\text {robus }-T}=\overline{A_{f-\text { robus }} \times\left(1-R_{-} P_{f}\right)} \\
A_{\text {robus }}=\bar{A}_{\text {robus }-T}
\end{array}\right.
$$

$R_{-} P_{f}$ is defined as follows. Suppose an existing force organization $\mathrm{O}_{f}$ has the resources $\left\{\left(r_{1}, N_{r_{1}}\right), \ldots,\left(r_{n}, N_{r n}\right)\right\}$. And the whole organization has the resources $\left\{\left(r_{1}, N_{A O r_{1}}\right), \ldots,\left(r_{n}, N_{A O r n}\right)\right\}$. Then $R_{-} P_{f}$ is defined as:

$$
R_{-} P_{f}=\frac{\sum_{i}^{N_{r_{i}}} / N_{A O r_{i}}}{n}
$$

So $R_{-} P_{f}$ compares the resources amount of the force organization and that of the organization it belongs to. Then the robustness of the organization measures not only the resources amount of its force organization, but also the efficiency of the force organizations.

\section{CASE STUDY}

This part we propose a case to analyze the robustness of organizations and verify the rationality of the robustness measure method.

The organization and its structure we used in this case is showed in Table 1.

TABLE I: THE ORGANIZATION STRUCTURE

\begin{tabular}{|l|l|l|l|l|}
\hline $\begin{array}{l}\text { Decisio } \\
\text { n Entity } \\
\text { ID }\end{array}$ & $\begin{array}{l}\text { Subordinat } \\
\text { e Decision } \\
\text { Entity ID }\end{array}$ & $\begin{array}{l}\text { Cooperate } \\
\text { Decision } \\
\text { Entity ID }\end{array}$ & $\begin{array}{l}\text { Executio } \\
\text { n Entity } \\
\text { ID }\end{array}$ & $\begin{array}{l}\text { Communicatio } \\
\text { n Entity ID }\end{array}$ \\
\hline 1 & & 26 & 1,2 & 3 \\
\hline 2 & & 23 & $3,4,5$ & 4 \\
\hline 3 & 2 & 28 & $6,7,8$ & 5 \\
\hline 4 & 3 & 19 & 9 & 3 \\
\hline
\end{tabular}




\begin{tabular}{|c|c|c|c|c|}
\hline 5 & 4 & & 10 & 2 \\
\hline 6 & 5 & & 11,12 & 3 \\
\hline 7 & & & 13 & 2 \\
\hline 8 & 6 & & $14,15,16$ & 4 \\
\hline 9 & 7 & & 17,18 & 3 \\
\hline 10 & 8,9 & 27 & 19,20 & 5 \\
\hline 11 & & & $21,22,23$ & 3 \\
\hline 12 & 10,11 & 24 & $24,25,26$ & 6 \\
\hline 13 & 12 & 17 & $27,28,29$ & 5 \\
\hline 14 & 13,15 & 20 & $30,31,32$ & 6 \\
\hline 15 & 16 & & 33 & 2 \\
\hline 16 & & & 34,35 & 2 \\
\hline 17 & 18,19 & $13,20,27$ & 36 & 6 \\
\hline 18 & 20,21 & 22 & 37 & 4 \\
\hline 19 & 22,23 & 4,28 & $38,39,40$ & 7 \\
\hline 20 & 24 & $14,17,21$ & 41,42 & 3 \\
\hline 21 & & 20,26,29, & 43 & 4 \\
\hline 22 & 25,26 & 18 & 44,45 & 5 \\
\hline 23 & 27,28 & 2,25 & 46,47 & 6 \\
\hline 24 & & 12 & 48,49 & 3 \\
\hline 25 & 29,30 & 23 & 50 & 4 \\
\hline 26 & & 1,21 & 51 & 3 \\
\hline 27 & & $\begin{array}{l}10,17,29,3 \\
0 \\
\end{array}$ & 52 & 5 \\
\hline 28 & & 3,19 & $53,54,55$ & 5 \\
\hline 29 & & \begin{tabular}{|l|}
$21,27,30$ \\
\end{tabular} & 56,57 & 5 \\
\hline 30 & & 27,29 & $58,59,60$ & 5 \\
\hline
\end{tabular}

The organization has 30 decision entities, 60 execution entities, and 106 communication entities. The task-mission space has 50 tasks.

First we generate force organizations and calculate their robustness. The result shows in Fig. 1

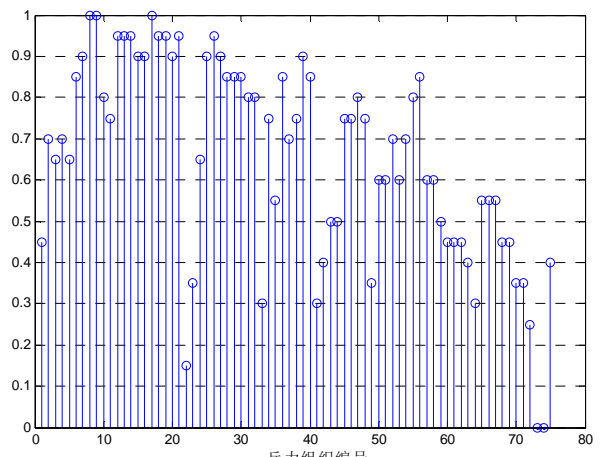

Fig. 1 The result of the robustness of force organizations

To verify the robustness measure method we change the tasks of those force organizations and calculate their task complete degree. We generate 30000 changed tasks. The result of task complete degree and the robustness of the force organizations are showed in Fig. 2.

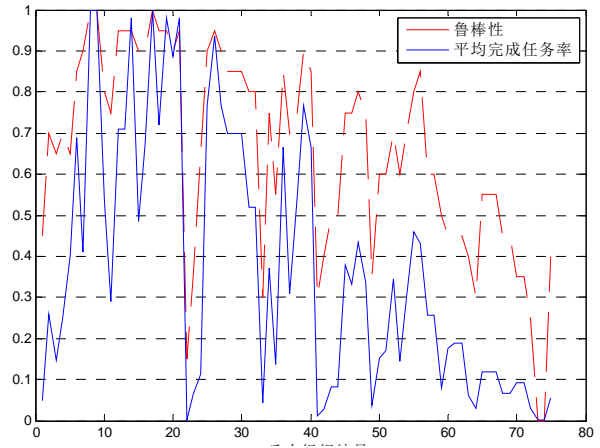

Fig. 2 Compares of changed tasks complete degree and robustness

From Fig. 2 we can see that the force organization with bigger robustness can complete more changed tasks. So the measure method is reasonable.

Second we calculate the robustness of the organization. According to the measure method we get the result the organization robustness. The result is showed in Fig. 3.

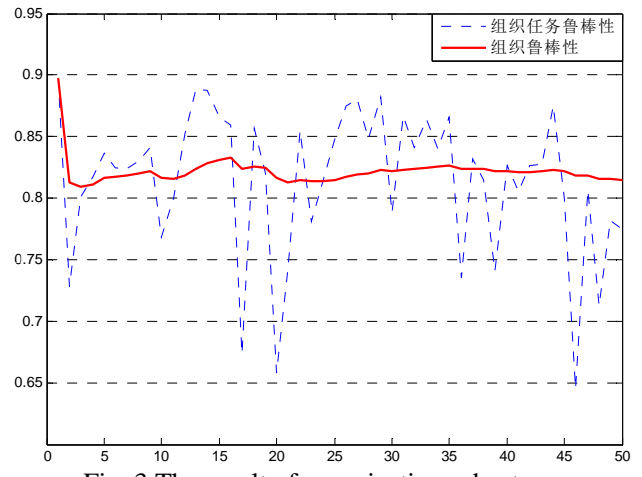

Fig. 3 The result of organization robustness

Organization robustness measure is a long-term and dynamic process. It is continuous changing with the changing of the tasks in the task-mission space.

\section{CONCLUSIONS}

This paper proposed a model of agile C2 organization and a measure method of the robustness. The model and method are verified by a case. But the case above is a simple case with small size of data set. In a real combat problem bigger organization and more complex missions will be involved. The agile C2 organization model need to be more calcuable and so it is with the robustness measure method . Case with real organizations are also needed to verify the model and method. So much work is needed in the future.

\section{REFERENCES}

[1] S. Alberts and R. E. Hayes. Power to the Edge: Command Control in the information Age, Information Age Transformation Series, CCRP Publications, 2003.

[2] Uschold II - King etc - The enterprise Ontology - The Knowledge Engineering Review, 1998.13(1) : 31-89

[3] Mike Uschold, Michale Grunniger - Ontologies: principles, methods and applications - The Knowledge Engineering Review, 1996.11.

[4] Xiu Baoxin.Design Methodology of C2 Organizational Structure and Its Analysis of Robustness and Adaptivity.2006

[5] Kathleen M. Carley and M. J. Prietula, Computational Organization Theory. Lawrence Erlbaum Associates. Hillsdale. NJ, 1994. 
[6] Kathleen M. Carley. Organizational Adaptation. Annals of Operations Research. 1998, 75: 25-47.

[7] Kathleen M Carley, Svoboda, D M. Modeling Organizational Adaptation as a simulated annealing process. Sociological Methods and Research, 1996, 25(1).

[8] Kathleen M Carley, Krackhardt D. A PCANS model of structure in organization. International Symposium on Command and Control Research and Technology, Monterray, CA. 1998.

[9] Kathleen M. Carley and Krackhardt, D. A typology for C2 measures. In: 1999 International Symposium on Command and Control Research and Technology, Newport, RI. 1999.

[10] David S. Alberts. The Agility Advantage A Survival Guide for Complex Enterprises and Endeavors, Monterey, , Sep. 2011,

[11] Jeffrey R. Cares • An Information Age Combat Model 2004.12.30.

[12] Dekker. A. H · Network Topology and Military Performance. Defense Science and Technology Organization , Australia 2005. 